\title{
The Impact of International Legal Rules in Facilitating the Public's Access to Medicines in South Africa
}

\author{
Vuyisile Hobololo \\ PhD candidate, University of the Witwatersrand, \\ Oliver Schreiner School of Law, Johannesburg \\ VuyisileH@armscor.co.za
}

This paper explores the role played by international legal treaties, conventions and agreements that are binding on South Africa, in promoting the public's access to medicines. In greater detail the impact that the Agreement on Trade-Related Aspects of Intellectual Property Rights (TRIPS) of 1994, the Convention on Biological Diversity of 1992, and the United States of America's Bahy-Dole Act of 1980 have had in the development of South Africa intellectual property (IP) law is examined. In addition, a question regarding whether such international legal instruments have positively impacted the public's access to medicines is considered.

The paper concludes that compliance with international IP law rules is not a silver bullet that will solve South Africa's challenges relating to access to medicines. The protection of the public's right to access to medicines in South Africa is strongly dependent on the government's political will of ensuring that IP law is implemented to serve public good and public and private pharmaceutical patent holders are held accountable regarding the socially-responsible utilization of their IP.

Research for this paper was funded by the Swiss State Secretariat for Economic Affairs under the SECO / WTI Academic Cooperation Project, based at the World Trade Institute of the University of Bern, Switzerland.

SECO working papers are preliminary documents posted on the WTI website (www.wti.org) and widely circulated to stimulate discussion and critical comment. These papers have not been formally edited. Citations should refer to a "SECO / WTI Academic Cooperation Project" paper with appropriate reference made to the author(s).

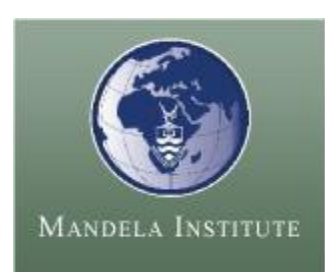




\title{
THE IMPACT OF INTERNATIONAL LEGAL RULES IN FACILITATING THE PUBLIC'S ACCESS TO MEDICINES IN SOUTH AFRICA
}

\author{
Vuyisile Hobololo*
}

This paper explores the role played by international legal treaties, conventions and agreements that are binding on South Africa, in promoting the public's access to medicines. In greater detail the impact that the Agreement on Trade-Related Aspects of Intellectual Property Rights (TRIPS) of 1994, the Convention on Biological Diversity of 1992, and the United States of America's Bayh-Dole Act of 1980 have had in the development of South Africa intellectual property (IP) law is examined. In addition, a question regarding whether such international legal instruments have positively impacted the public's access to medicines is considered.

Having established that that the South African Patents Act of 1978 was generally substantively compliant with TRIPS even prior to its post-TRIPS amendments, it appears that a number of amendments discussed herein appeared to seek to achieve textual compliance as they were already TRIPS-compliant. For South Africa, one of the key challenges is that accession to TRIPS appears to have diminished the country's autonomy to overhaul or amend IP legislation in line with the 1996 Constitution of the democratic South Africa that upholds the public's right to healthcare services, among other fundamental human rights.

The higher standards of IP protection entrenched in TRIPS may compromise public's access to medicines in any developing country (DC) or least developed country (LDC) that lacks institutional capacity or political will to implement compulsory licensing in the public interest whenever the public’s right to access medicines is threatened by pharmaceutical patentees' abuse of patent rights.

On the other hand, the CBD appears to have positively affected the development of national law as it influenced the promulgation of the National Environmental Management Biodiversity Act (NEMBA) in 2004 and the amendment of the Patents Act in 2005 which jointly protect the rights of indigenous knowledge (IK) holders. With South Africa being the third most bio-diverse country in the world, and also having wealth of IK relating to pharmaceuticals the NEMBA and the 2005 amendment of the Patent Act have established clear rules to guard against bio-piracy. The benefit-sharing provisions of the NEMBA however appear to limit the right to benefit sharing to only a share or portion of commercialization of income realized by the bio-prospector. A suggestion is made to extend the benefit-sharing to include the right to co-own the IP in question as the portion of commercialization income that does not guarantee the public's access to the pharmaceutical products developed from IK.

It was also noted that while Bayh-Dole has positively influenced the promulgation of the Intellectual Property Rights from Publicly-Financed Research and Development Act of 2008 (IPR Act), 
ownership of IP by public institutions will only be meaningful for the realization of the public's right to access medicines when the public institutions owning the IP are legally obliged to utilize the IP in the public interest. Currently, public institutions may use their discretion regarding whether they should pursue revenue-driven or people-focused transactions. The IPR Act neither offers any penalty to, nor holds accountable, any public institution that prioritizes revenue over public good.

It can therefore be concluded that compliance with international IP law rules is not a silver bullet that will solve South Africa's challenges relating to access to medicines. The protection of the public's right to access to medicines in South Africa is strongly dependent on the government's political will of ensuring that IP law is implemented to serve public good and public and private pharmaceutical patent holders are held accountable regarding the socially-responsible utilization of their IP.

\section{INTRODUCTION}

The legal standards expressed in international trade agreements, treaties and conventions to which South Africa has acceded dictate the confines within which policy makers and law makers may tread when constructing or reviewing national law and policy. Therefore, if South Africa were to overhaul its intellectual property (IP) law regime, as proposed by some scholars, ${ }^{1}$ to enhance the public's access to patented medicines, the substance of the legal provisions giving effect to such law reforms or revised policy direction will inevitably have to be informed by the spirit of the relevant international agreements such as the Agreement on Trade-Related Aspects for Intellectual Property Rights (TRIPS), and to some extent the Convention on Biological Diversity (CBD) which pays specific attention to legal issues at the interface of IP, indigenous knowledge (IK) and biodiversity.

TRIPs and the legal developments related thereto serve as both an international legal sounding board and a major instrument of analysis when dealing with the question of promoting access to essential medicines in WTO member states. The compelling evidence of the value of IK in developing pharmaceutical products from biodiversity strengthens the case for considering the role that the international legal rules in the CBD may play in improving access to patented medicines developed from indigenous genetic resources, biological resources, or IK for the people of South Africa. However, it is also important to recognize the impact of the Paris Convention which is also an important and long-established reference point in the development of international IP law.

\footnotetext{
* PhD candidate, Oliver Schreiner School of Law, University of Witwatersrand, Johannesburg. Visiting Research Fellow, World Trade Institute, University of Bern, Switzerland. M.Sc (Stellenbosch), Master of Intellectual Property Law and Management (Strasbourg).

${ }^{1}$ C Park, A Parbhala and J Berger 'Using Law to Accelerate Treatment Access in South Africa - An Analysis of Patent, Competition and Medicines Law' (2013), United Nations Development Programme Report; Y A Vawda 'Access to Life-Saving Medication in South Africa: The Case for Legislative Reform (2010) LLD Thesis submitted at the University of KwaZulu-Natal.
} 
In addition to the binding international IP legal rules such as those entrenched in treaties and conventions, as indicated above, the manner in which South Africa may improve the public's access to patented medicines may also be influenced by the success that other countries have witnessed following their implementation of certain IP legislation such the Bayh-Dole Act of 1980 in the United States of America. Legal borrowing and transplantation of this US legislation has been espoused and implemented by many developed countries and a few developing countries (DCs) such as South Africa, ${ }^{2}$ Brazil, ${ }^{3}$ the Philippines, ${ }^{4}$ India, ${ }^{5}$ and others.

The progress made by India, China and Russia to date in this regard indicates the substantial buy-in of the Brazil-Russia-India-China-South Africa (BRICS) countries into the Bayh-Dole type of lawmaking and this promises numerous opportunities for local economic development in these countries. This may have positive trade implications among the BRICS countries themselves and among them and the world at large.

The said legislation revolutionized R\&D collaborations between the private sector, including the pharmaceutical multinational companies, and the public R\&D institutions such as universities and science councils by vesting the right to own the IP emanating from federally-funded R\&D with the public R\&D institutions. ${ }^{6}$ Therefore, the South African Bayh-Dole type of legislation enacted in 2008 in the form of the Intellectual Property Rights from Publicly-Financed Research and Development Act (IPR Act) similarly provides that recipients of public R\&D funds will own the IP resulting from the $R \& D$ in question. ${ }^{7}$ In this regard, publicly-funded R\&D institutions such as the South African Medical Research Council (SAMRC) and others conducting health-related R\&D can now own IP developed from public funds, and subsequently prioritize public interest when utilizing or commercializing such IP.

However, some exceptions such as co-ownership of IP under certain circumstances is possible, ${ }^{8}$ and IP ownership is negotiable and does not arbitrarily vest in public R\&D institutions where R\&D is

\footnotetext{
${ }^{2}$ South African Intellectual Property Rights from Publicly-Financed Research and Development Act of 2008. (Act No. 51 of 2008).

${ }^{3}$ E Stahl and A Fujino. 2016. The evolution of universities' relations with the business sector in Brazil: what national publications between 1980 and 2012 reveal. R. Adm., Sao Paulo, v. 51, n. 1, pp. 72-86.

${ }^{4}$ Philippine Technology Transfer Act of 2009 (Republic Act No. 10055).

${ }^{5}$ S Basheer. 2010. Outsourcing 'Bayh-Dole' to India: lost in transplantation. Columbia Journal of Asian Law, Vol. 23, No. 2 (Available at ssrn:http//ssrn.com/abstract=1546403).

${ }^{6}$ V. L Hobololo. 2015. Intellectual property co-ownership and commercialization in public-private partnerships in South Africa. Proceedings of International Association for Management of Technology (IAMOT 2015) conference, pp.2627.

${ }^{7}$ This legislation came into effect in August 2010 when it was promulgated. Between 2008 and 1 August 2010 the Regulations relating to the implementation of this legislation were still being finalized and as a result the IPR Act was not legally-binding on the recipients of public funds at that stage.

${ }^{8}$ Such circumstances are provided in s15(2) of the IPR Act as follows: the IP in question must have been jointly-created by the parties seeking to co-own, the IP in question must have been developed from the resources contributed jointly by parties seeking co-ownership, a benefit-sharing agreements detailing how the IP creators
} 
funded by a private company on a full cost basis. ${ }^{9}$ This legislation appears to hold a very dear promise for the public as it empowers publicly-funded R\&D institutions to build IP portfolios across all technology sectors, including pharmaceuticals, with the specific purpose of utilizing such IP in a manner that gives priority to public good.

This model of IP utilization is unprecedented within the South African IP regime and in direct contrast to the revenue-driven manner of IP commercialisation that is synonymous with pharmaceutical multinational companies and industry in general. Certainly, the South African Patents Act of 1978 does provide for compulsory licensing (CL) when its implementation is in the public interest. ${ }^{10}$ Unfortunately, the practical implementation of this mechanism has to date not taken place in South Africa.

Government use of patented inventions, also provided in the South African Patents Act, ${ }^{11}$ is a mechanism similar to CL as it defines the right that may be exercised by the State to override the exclusive right of the patent holder so as to address a public health crisis, or any other situation deemed by the State to be of extreme urgency. The manner in which these mechanisms are implemented however has to be in compliance with the TRIPS Agreement. ${ }^{12}$

The crucial legal developments, pertinent to the public's access to medicines, that have surfaced since the adoption of TRIPS in 1994 are the 2001 Doha Declaration on the TRIPS Agreement and Public Health, the 30 August 2003 Decision of the WTO which introduced a waiver of certain provisions of Article 31 of TRIPS, and the amendment introduced by the 6 December 2005 Decision seeking to give effect to the waiver suggested in the preceding Decision. These developments will be examined in this chapter to establish the role that they have played or can play in improving access to essential medicines within the context of a developing country such as South Africa.

The purpose of this paper is therefore to critically analyse the role played by the above, with specific focus on TRIPS, in the development and implementation of legislation and policy that seek to advance the State's efforts of improving the public's access to essential medicines in South Africa. More importantly, this paper will further evaluate the compliance status of the South African IP law regime with international standards. Furthermore, the study considers implementation of limited exceptions and flexibilities accorded in TRIPS, which are mechanisms purposed at ensuring that exclusive rights of the patent holders do not compromise the efforts made by the State towards improving access to essential medicines for even the poorest members of the public.

based at the university or science council will be compensated must be concluded, and lastly there must a commercialization agreement concluded between the parties.

${ }^{9}$ Section 15(4).

${ }^{10}$ Section 56(2)(d).

${ }^{11}$ Section 4 and Section 78.

${ }^{12}$ Art 30 and 31. 
Such analysis will be presented in six parts, with Part I being the introduction; Part II providing a broad overview, purpose and background of TRIPs; Part III, an evaluation of the extent to which the current South African IP regime complies with TRIPs; Part IV reflecting on the influence of legal developments relating to TRIPS and their impact on access to medicines; Part V, the influence that the CBD and the US Bayh-Dole Act have had in the development of South African IP law; and lastly with Part VI providing the conclusion and suggestions on how South Africa can strategically implement the public health-focused legal provisions entailed in international standards.

\section{INTERNATIONAL LEGAL STANDARDS}

\section{a) TRIPS Agreement: Background and Purpose}

The adoption of TRIPS took place in 1994 in Morocco during the Uruguay round of the multilateral trade negotiations of the General Agreement on Trade Tariffs (GATT), when the World Trade Organisation (WTO) was established. One of the controversial elements of TRIPS is that WTO membership was pre-conditioned on the non-negotiable accession to this Agreement leading to obligatory espousal of higher standards of IP protection.

Developing countries such as Brazil, China, India and many others had consistently played a significant role in blocking and expressly opposing the inclusion of IP in the GATT multilateral trade negotiations. However, the all or nothing model that married international trade to IP made it difficult for developing countries and least developed countries to reject WTO membership as they believed that it was essential for their international trade interests.

Indeed, TRIPS was a quid pro quo type of an agreement or a balancing act where DCs such as South Africa and LDCs were offered access to markets of the developed world in exchange of the increased levels of IP protection. ${ }^{13}$ For South Africa, WTO membership also carried the benefit of the lifting of sanctions and re-integration into the international trade community. Such sanctions had been placed on South Africa as a result of the apartheid regime that governed South Africa through implementation of inhumane and racial laws and policies at the time TRIPS was adopted.

In addition to the minimum standards of IP protection, TRIPS also prescribes protectable subjectmatter that WTO member states must provide for in their national laws, and for dispute resolution in relation to IP rights. Although TRIPS purportedly introduced only the minimum standards which allow WTO member states to, if they so desire, provide for higher standards in their national laws, it

\footnotetext{
${ }^{13}$ A. Kamperman-Sanders and D.B. Shabalala. 2014. Intellectual property treaties and development. In D. Gervais (ed.), Intellectual Property Trade and Development, Oxford University Press, Available at SSRN:http://ssrn.com/abstract=2178423.
} 
is important to note that such minimum standards were and are still very high for most developing countries and least developed countries, as they were more in line with the standards of IP protection that existed at the time in developed countries such as the USA and the European Union.

A practical example being that many developing countries such as Argentina, Brazil, India and others did not, prior to TRIPS, provide for patenting of pharmaceutical inventions. In order to ensure that all WTO member countries gradually met the higher standards of IP protection, specific time-frames were then set for DCs, economies in transition, and LDCs by which compliance with the new and higher standards of IP protection had to be achieved. Whilst the idea of transitional arrangements might have appeared logical and considerate at the time as it purported to enable the less developed WTO member states to effect new and higher standards of IP protection over a 'reasonable' period of time, it is clear that the applicable time periods could not have been well thought out as they appear and unrealistic for many DCs and LDCs. ${ }^{14}$

Arguably, these transitional arrangements were only pretentious and strongly appear to be some kind of double standards advanced by the developed member states given that the developed member states only heightened their levels of IP rights protection to the level required by TRIPS after several decades of developing the requisite knowledge base, infrastructure, and technical know-how and experience in executing advanced and well-funded R\&D programmes in the pharmaceutical sector and other fields of technology and without the pressure of having to meet any external requirements such as compliance with international trade law instruments. ${ }^{15}$ Adoption of high standards of IP rights by a country that has not taken any substantial strides in innovative research and development (R\&D) or mobilized the afore-stated requisite innovation building blocks raises serious questions regarding the benefits of such a regime for the DCs and LDCs. ${ }^{16}$

The fact that the LDCs have been continuously requesting further extensions regarding their date of compliance with TRIPS, save the non-negotiable compliance with Articles 3, 4 and 5, might be an indication that the LDCs can hardly see the benefit of adopting higher standards of IP protection or the value of practically implementing TRIPS in their national laws. The most recent extension requested on 5 November 2012 by Haiti on behalf of LDCs, pursuant to Article 66.2 of TRIPS, was effected in June 2013 to further extend the deadline for LDC's compliance with TRIPS obligations to 1 July 2021.

\footnotetext{
${ }^{14}$ Article 65 of the TRIPS Agreement provides for Transitional Arrangements which indicate amount of time that least developed countries and developing countries were given to comply with the TRIPS Agreement.

${ }^{15}$ G Ghidini 'On TRIPS impact on least developed countries': the effects of a double-standard approach' (2014). TRIPS and developing countries: Towards a new intellectual property world order? (eds) G Ghidini, JR Rudolph and PM Ricolfi.

${ }^{16}$ Ibid.
} 
This extension brought some confusion as the Doha Declaration on TRIPS and Public Health had on 14 November 2001 already specifically indicated that LDCs were not required to comply with the specific requirement of patenting pharmaceuticals before 1 January 2016. The scope of the transitional arrangements to which the 1 July 2021 deadline relates, is much broader than the provisions relating to protection and enforcement of IP rights relating to pharmaceutical innovations entailed in paragraph 7 of the Doha Declaration.

It therefore follows that LDCs may legitimately postpone their compliance with requirement the TRIPS Agreement relating to protection and enforcement of IP rights to 1 July 2021 as such may be read to form part of the extension granted thereto concerning LDCs' compliance with the TRIPS Agreement. Inadvertently, the WTO's interpretation of the implications of the respective extensions is that LDCs are obliged to comply with the Doha Declaration requirement of providing for patenting of pharmaceuticals by January 2016, and may consider the July 2021 extension to only apply in relation to other provisions of the TRIPS Agreement.

The apparent lack of interest displayed by many LDCs in being bound by TRIPS is not surprising given that this Agreement was concluded through coercion of the LDCs and DCs by the developed countries. ${ }^{17}$ Several scholars have written on how economic coercion has been used in the legal transplant of the United States of America-type of IP rules, ${ }^{18}$ and they concur that coercion was instrumental in the discussions preceding the conclusion of the TRIPS Agreement.

Sell's detailed account on the coercive character of the TRIPS Agreement summarily argues that the TRIPS Agreement has negatively affected the LDCs and DCs in relation to the public's access to medicines. ${ }^{19}$ The developed countries strongly appear to have been the architects and consequently beneficiaries of this Agreement, whilst the less developed countries largely remain victims seeking to minimize its negative impact, thus Sell aptly remarks that:

'If it had not been for twelve American-based transnational corporations of the Intellectual Property Committee (IPC), there would be no TRIPS today. Without TRIPS there would be no Access to

\footnotetext{
${ }^{17}$ J-F Morin and E.R Gold. 2014. An integrated model of legal transplantation: the diffusion of intellectual property law in developing countries. International Studies Quarterly, Vol. 58(4), pp.781-792. DOI:10.1111/isqu.12176.

${ }^{18} \mathrm{~J}$ Braithwaite and P Drahos. 2000. Indigenous Knowledge, Intellectual Property and Biopiracy: Is global biocollecting society the answer. European Intellectual Property Review, Vol. 22(6), pp 245-250; C May and SK Sell. 2006. Intellectual property rights: a critical history. Boulder Publishers; KC Shadlen. 2004. Challenges to treatment: the price-infrastructure trap and access to HIV/AIDS drugs. Journal of International Development, Vol. 16(8), pp. 1169-1180. DOI:10.1002/jid.1170; K Zeng. 2002. Complementary trade structure and US-China negotiations over intellectual property rights. East Asia.

${ }^{19}$ SK Sell 'Post-TRIPS Developments: The tension between commercial and social agenda in the context of intellectual property' (2001). 14 Fla, J Int'l L 193; SK Sell 'Intellectual Property Protection and anti-trust in the developing world: crisis, coercion and choice’' (2002) International Organisation 49, pp. 315-349.
} 
Medicines Campaign. Finally, without Access to Medicines Campaign there would be no Doha Declaration on TRIPS and Public Health, ${ }^{20}$

Her argument supports the view that the TRIPS Agreement was exclusively drafted in favour of the business interests of the developed member states of the WTO, and more specifically the pharmaceutical multinational companies in the developed states, as such interests took precedence over the concerns raised by more than fifty DCs and LDCs who fiercely opposed the adoption of the Western standards of IP protection.

Concurring with this viewpoint, Visser opines that this Agreement is purely a representation of the will of the developed states and not that of the DCs and LDCs. ${ }^{21}$ He further qualifies his assertion by pointing out that all what the DCs and LDCs sought during the negotiations was a code against counterfeit goods, while the developed states advocated for stronger IP laws.

The IP norm-setting and policy-making dynamics that informed the conclusion of TRIPS did not satisfy the three requirements of representativity, as not all interested parties were represented; full information, as all the parties involved needed to have had the full information about consequences of various possible outcomes, and non-coercion, as none of the parties had to coerce any other. ${ }^{22}$

While the proponents of the incentive theory relating to the patent system advocate for strong IP laws, the weaker patent regimes in DCs such as India have positively contributed to the development of well-established generics manufacturing industries, and consequently to the lower cost of pharmaceuticals, one of the key pre-requisites for the public’s improved access. ${ }^{23}$

Sell's specific reference to the prioritization of the private interests of pharmaceutical executives in TRIPS and the challenges that this Agreement has placed on the public's access to medicines somewhat threaten the capacity of follow-up instruments such as Doha Declaration on the TRIPS Agreement and Public Health, and the amendment premised on the 2003 and the 2005 Decisions of the TRIPS General Council, which are all based on and remain the derivatives of the same Agreement, to practically strike a balance between the private interests of patent holders and the public rights of the impoverished society.

\footnotetext{
${ }^{20}$ SK Sell. 2002. 'TRIPS and the Access to Medicines Campaign' (2001). Proceedings of the 2002 Conference on Access to Medicines in the Developing World: International Facilitation or Hinderance? Panel \#2: TRIPS and Access to Medicines Campaign. Wisconsin International Law Journal 20, pp. 481-522.

${ }^{21} \mathrm{C}$ Visser 'Affordable medicines exceptions to patent rights under the TRIPS Agreement: some pointers for South Africa?. (2001). Comparative and International Law Journal of Southern Africa, Vol. 34, pp. 377-396.

${ }^{22} \mathrm{C}$ Visser 'The policy-making dynamics in intergovernmental organizations: A comment on the remarks of Geoffrey Yu’ (2007) Chicago-Kent Law Review Vol. 82(3), pp. 1457-1466.

${ }^{23}$ NA Bass 'Implications of the TRIPS Agreement for developing countries: Pharmaceutical patent laws in Brazil and South Africa in the $21^{\text {st }}$ century’ (2002) George Washington International Law Review, p191.
} 
With South Africa being a DC, accession to TRIPS does not appear to have been of much assistance in improving the public's access to patented medicines. However, this assertion cannot be confirmed without interrogating the extent to which the South African IP regime has evolved in compliance with TRIPS, and possibly how such evolution, if any, has advanced the cause of improving the public's access to patented medicines. The following section evaluates the level of the South African patent legislation's compliance with the TRIPS Agreement, while also examining if the current IP landscape in South Africa can really be attributed to TRIPS as the local landscape was substantially developed, even to provide for CL, prior to the adoption of the TRIPS Agreement.

\section{South Africa's compliance with the TRIPS Agreement: Critical Legal Provisions Relating to Pharmaceuticals}

\section{Protectable subject-matter}

Extending patent protection to all fields of technology, provided that the novelty, inventiveness and industrial applicability requirements are met, is one of the most revolutionary provisions of the TRIPS Agreement, ${ }^{24}$ as it implied that DCs such as India that previously did not provide for patent protection in relation to products, including pharmaceuticals and food, had to within a specified maximum period of 10 years amend their national legislation to comply accordingly.

When asserting the competence and sensitivity of the TRIPS Agreement in dealing with the public health crises such as HIV/AIDS, TB, malaria and other epidemics, paragraph 7 of the Doha Declaration on TRIPS and Public Health revised the cut-off date for LDCs to comply with the requirement of offering patent protection in respect of pharmaceutical inventions. In terms of the said paragraph, and as briefly mentioned above, the TRIPS Council gave the LDCs until 1 January 2016 to amend their patent laws to provide for patenting of pharmaceutical inventions.

However, s 25 of the South African Patents Act of 1978 was already substantively in agreement with the content of what became the provisions of Art 27.1 of the TRIPS Agreement in 1994 as it already provided, and still provides, for patenting of any invention which is new, involves an inventive step, and capable of being applied in industry, trade or agriculture. ${ }^{25}$ Reference, in the TRIPS Agreement, to 'any invention' certainly includes pharmaceutical inventions. This is further evidence that patenting of pharmaceutical inventions was already provided in South African patent law long before the adoption of the TRIPS Agreement.

\footnotetext{
${ }^{24}$ Art 27.1.

${ }^{25}$ Section 25(1).
} 
TRIPS also requires members to provide for the extent of disclosure of the subject-matter of the inventions in their national laws, as Article 29.1 requires disclosure that is sufficiently clear and complete such that the invention can be carried out by a person skilled in the art. Furthermore, the applicant must indicate the best mode for carrying out the invention known to the inventor at the filing date or, where priority is claimed, at the priority date of the application.

The original position of the SA Patents Act of 1978 in terms of s 32(3) was already substantively in agreement with TRIPS ${ }^{26}$, but has been amended to provide as follows:

'A complete specification shall-

(a) have an abstract as prescribed;

(b) sufficiently describe, ascertain and, where necessary, illustrate or exemplify the invention and the manner in which it is to be performed in order to enable the invention to be performed by a person skilled in the art of such invention; and

(c) .......

(d) end with a claim or claims defining the invention for which protection is claimed.'

However, the 2002 amendment of sub-section 3 wherein s 1 of the Patents Amendment Act No. 58 of 2002 was introduced brought national patent law to what appears to be textual compliance with Art 29.1 of the TRIPS Agreement. The original position provided as follows:

'A complete specification shall -

(a) Have an abstract as prescribed;

(b) Sufficiently describe, ascertain and, where necessary, illustrate or exemplify the invention and the manner in which it is to be performed in order to enable the invention to be performed by the person skilled in the art of such an invention; and

(c) Disclose the best method of performing the invention known to the applicant at the time when the specification is lodged at the patent office; and

(d) End with a claim or claims defining the invention for which protection is claimed.'

The extent of disclosure in a patent application is a very important requirement of South African patent law, and non-compliance with this provision may lead to revocation of a granted patent in terms of s 12 of the Patents Amendment Act of 2002 which amended s 61(1)(e) of South African Patents Act of 1978.

This amendment appears to be largely symbolic of South Africa's interest in demonstrating willingness to comply with TRIPS as the current version is hardly a substantial deviation from the

\footnotetext{
${ }^{26}$ Section 31(d) of the Intellectual Property Laws Amendment Act 38 of 1997.
} 
original, pre-TRIPS position. Most of the post 1994 amendments in South African patent law are in the same vein, the intention appears to have been more about amending provisions that were already substantively compliant to bring them to textual compliance, which translates to doing somewhat more than what the TRIPS Council expected of WTO member countries.

\section{Effect of a patent}

The South African Patent Act ${ }^{27}$ substantively complies with Article 28 of the TRIPS Agreement as they both provide that patent holders are entitled to the exclusive rights of making, using, offering for sale, selling, and importing for the same purpose the patented invention. The South African Patents Act further provides that such exclusive rights are granted so that the patent holder may 'have and enjoy the whole profit and advantage accruing by reason of the invention'.

The Intellectual Property Laws Amendment Act No. 38 of 1997 also introduced an amendment to s 45 of the Patents Act that was already substantively compliant with Art 28 of the TRIPS Agreement. The 'whole profit and advantage accruing by reason of the invention' appears to accommodate strategic use of patent rights which some scholars ${ }^{28}$ perceive as abusive of patent rights. In the pharmaceutical sector, where such strategies are more prevalent, these practices may include filing patents to block competitors, or in anticipation of business interests of other parties, or extraction of maximum revenue from patent portfolio even through mechanisms such as ever-greening. ${ }^{29}$ This may not be the intention of this legislation, but it appears that the language of the legislators may be interpreted to afford patent holders more rights than it is intended or required by the TRIPS Agreement.

\section{Term of protection}

Article 33 of the TRIPS Agreement provides that patent rights must be enjoyed for a period of at least 20 years, meaning that WTO member states may provide for longer periods in their national laws. In compliance with this Agreement, s 44 of the SA Patents Act also provides that protection is valid for a period of 20 years counted from the filing date. Within the pharmaceutical industry, most medicines become available in the market after a period of approximately 15 years from the first filing date. In such situations the patent holder practically has about 5 years to work the invention. This may be part of the reason some patent holders resort to abusing patent rights by excessively pricing the patented medicines.

\footnotetext{
${ }^{27}$ Section 45.

${ }^{28}$ See Hill supra, 21. V Hobololo. 2015. Strategic patenting of pharmaceutical inventions and the public's right to access medicines: The South African context. The African Journal of Information and Communication, p.78.

${ }^{29}$ Ibid.
} 
The result is that the public's right to access medicines thus gets undermined. That is why Visser suggests that, in the light of all the regulatory approvals and other time-consuming formalities that precede availability of patented medicines in the market, a consideration be made to increase the term of patent protection in such cases. ${ }^{30}$ However, there is no evidence that such concession would positively influence the behaviour of pharmaceutical multinational companies, as much as there is no evidence that the current term of protection is the reason for excessive pricing of medicines.

\section{Abuse of patent rights}

In line with Article 30, 31 and 40(2) of the TRIPS Agreement which provide for mechanisms purposed at limiting the abuse of patent holder's private rights against the public or competitors such as manufacturers of generic medicines, sections 4, 55, 56 and 78 of the South African Patent Act similarly provide for government use and CL to ensure that the public's right to access medicines is not compromised. These provisions therefore ensure that the exclusive rights of patent holders are not absolute and should they be abused, the granting state must be able to effect corrective action that protects the public from such abuse by the patent holders. The South African Consumer Protection Act, and the Competition Act also provide for protection of the public from excessive pricing, and anti-competitive behaviour of sellers and manufacturers such as pharmaceutical companies.

\section{Undisclosed information}

WTO member states have an obligation in terms of Art 39 of the TRIPS Agreement to provide, in their national laws, for protection against unfair commercial use of undisclosed information such as trade secrets, certain test data or any other data submitted to State agencies. In order to expedite the availability of generic versions of patented medicines in the market, s 16 of Act No. 58 of 2002 amended the South African Patent Act to introduce s 69A which is often referred to as the Bolar provision. This provision allows other parties to conduct $R \& D$, test studies, manufacture or perform other related acts such as seeking regulatory approvals on pharmaceutical inventions that are still under valid patent protection.

In terms of s 69A (1) and (2), manufacturers of generic medicines can now rely on clinical data and related information of patented medicines when seeking marketing approvals for generics even before the patents expire. Therefore, manufacturing patented medicines on a non-commercial scale solely for purposes of seeking such approvals is in terms of South African not deemed to amount to infringement. This amendment has played a major role in mitigating time delays of bringing generic

\footnotetext{
${ }^{30}$ See Visser supra, 16; V Hobololo. 2015. Strategic patenting of pharmaceutical inventions and the public's right to access medicines: The South African context. The African Journal of Information and Communication, p.78.
} 
medicines to the market, as the generics manufacturers can rely on the patentees' clinical data that is already at the regulatory authorities’ disposal.

\section{The influence of international standards in the evolution of South African Patent Law}

\section{a) Doha Declaration on the TRIPS Agreement and Public Health}

While this Declaration is often cited as a crucial international law instrument that escalated the link between IP and public health issues into international platform, there is not much that it changed regarding how WTO member states, and inevitably South Africa, dealt with public health challenges and promotion of access to medicines. This is because the substantive provisions of the Declaration are largely a re-iteration or re-affirmation ${ }^{31}$ of the TRIPS Agreement on public access to medicines.

However, the TRIPS flexibilities offered by the Declaration are very crucial although appearing as some form of damage control instrument designed to manage the negative consequences of the adoption of the TRIPS Agreement by LDCs and DCs. The flexibilities summarily emphasize that although TRIPS was a take it or leave it package deal that introduced the higher standards of IP protection for most DCs and LDCs, its spirit still remains sensitive to the plight of DCs and LDCs particularly in so far as issues of access to medicines are concerned.

Consequently, the Declaration unequivocally attempted to clarify the WTO position that member countries were allowed to implement CL in their national laws. Although TRIPS provides for the limiting of patent holders' exclusive rights, it is only in the Doha Declaration that express reference to CL is made. WTO member states such as South Africa that had legislation that already provided for CL are expressly protected by this provision of the Declaration. The other notable flexibility introduced by the Declaration is the extension of cut-off date by which LDCs have to comply with the requirement of implementing IP protection with respect to pharmaceuticals. ${ }^{32}$

Another appreciable contribution of this Declaration was the tightening of accountability levels thrust on the TRIPS Council. This is evident in the specific mandate given to the TRIPS Council to ensure that they developed a practical solution or plan, within a defined time period, detailing how the DCs and LDCs that lacked or had insufficient capacity to manufacture pharmaceuticals ${ }^{33}$ could be enabled to effectively implement CL provisions provided in Art 30 and 31 of the TRIPS Agreement, and paragraph 5(b) of the same Declaration.

\footnotetext{
${ }^{31}$ Paragraph 4 of the Doha Declaration re-affirms the right, already provided in the TRIPS Agreement, of WTO member states to use provisions relating to TRIPS flexibilities.

${ }^{32}$ Para 7 of the Doha Declaration.

${ }^{33}$ Par 6 of the Doha Declaration.
} 
The right to implement CL does not bear much meaning for a country that lacks capacity in the form of the requisite technical and intellectual capacity and infrastructure to actually work the invention. The fact that the mandate given to the TRIPS Council had a timeline expiring within just over a year indicated some sense of urgency that DCs and LDCs placed on the matter. It might also be argued that DCs and LDCs were in the main compelling the TRIPS Council to ensure that the provisions of the Art 66.2 of the TRIPS Agreement were implemented. This Article provides that:

'Developed country Members shall provide incentives to enterprises and institutions in their territories for the purposes of promoting and encouraging technology transfer to least-developed country Members in order to enable them to create a sound and viable technological base'.

This provision placed an obligation on developed WTO members states such as the US and EU to stimulate their pharmaceutical industry to invest in DCs and LDCs by, for example, setting up pharmaceutical manufacturing infrastructure in these DCs and LDCs, or transfer pharmaceutical development and manufacturing skills in one way or another so as to contribute in technology transfer. It is the responsibility of the developed WTO member states to ensure that their pharmaceutical industry is adequately incentivized for the fulfilment of this provision, as without technology transfer and technical cooperation ${ }^{34}$ the CL provisions, even when entrenched in national laws of the LDCs and DCs, will only be tantamount to dummy clauses that do not bear much meaning.

This presents tremendous opportunities for South Africa to use its relatively developed infrastructural capacity to establish strategic trade partnerships with other African countries wherein pharmaceuticals or elements of the pharmaceutical manufacturing value chain may be produced in South Africa and exported to such other countries.

\section{November 2003 Decision}

The 2003 Decision was a progressive step towards implementation of paragraph 6 of the Declaration as it recognized the challenges faced by some countries, mainly LDCs due to lack of adequate pharmaceutical manufacturing capacity. As a result this justified the deviation from the provisions of Art 31(f) and (h) when implementing compulsory licensing.

\footnotetext{
${ }^{34}$ Art 67 provides for technical cooperation between the developed WTO member states and DCs and LDCs.
} 
This meant that implementation of CL or government use did no longer have to be predominantly for supplying domestic markets. ${ }^{35}$ Effectively, this introduced a waiver of export restrictions, imposed by Art 31(f), only with respect to pharmaceuticals. South Africa has previously enabled other Southern African countries access to anti-retroviral drugs (ARVs) through licences that were granted by two pharmaceutical companies to South Africa. The outcome of the Hazel Tau and others $v$ GlaxoSmith Kline (GSK) and Boehringer Ingelheim (BI) case wherein the complainants alleged excessive pricing of ARVs by GSK and BI however cannot be regarded as the implementation of the 2003 Decision per se as the licenses in question were not compulsory licenses but voluntary licenses.

The deviation from the said provisions of the TRIPS Agreement, in terms of the 2003 Decisions means therefore that in order to address the pharmaceutical manufacturing capacity-related challenges of some WTO countries, the WTO member countries with adequate capacity are allowed to manufacture not only for their domestic markets, but may also export the pharmaceuticals manufactured under a CL, to foreign markets where there is lack of or insufficient capacity to manufacture the licensed medicines in their jurisdiction.

In ensuring that this exception or waiver is not abused, the Annexure to this Decision provides a guideline on which countries may be deemed as having insufficient or no manufacturing capacity in the pharmaceutical sector.

The products to which this Decision apply are also defined ${ }^{36}$, the eligible importing member $^{37}$, and exporting member. ${ }^{38}$ The painstaking formalities of this Decision, include: the notification that the importing country must make to the TRIPS Council ${ }^{39}$ specifying the names and expected volume of the product needed, confirm that its eligibility in terms of par 1(b) and Annex of this Decision ${ }^{40}$, and where a medicine is patented in its jurisdiction it has granted or intends to grant a CL pursuant to Art 31 and the provisions of this Decision ${ }^{41}$.

This Decision also prescribes that the CL granted under this system must specify that only the amounts necessary to meet the needs of the importing country may be manufactured and that such manufactured amounts shall in whole be exported to the importing member who have notified TRIPS Council of its needs. ${ }^{42}$ Furthermore, the said products must be clearly identified and labelled as being produced under this Decision, and that the licensee must prior to shipment post on their website

\footnotetext{
${ }^{35}$ Art 31(f).

${ }^{36}$ Par 1(a) of the 2003 Decision.

${ }^{37}$ Par 1(b).

${ }^{38}$ Par 1(c).

${ }^{39}$ Ibid.

${ }^{40}$ Par 2(a)(ii).

${ }^{41}$ Par 2(a)(iii).

${ }^{42}$ Par 2(b)(i).
} 
information relating to quantities being supplied to each destination, and the distinguishing features of these products. ${ }^{43}$

The exporting member also has an obligation to notify TRIPS Council of the grant of the license, indicating the name and address of licensee, the products for which license has been granted, the quantities for which it has been granted, the country to which the product is to be supplied and the duration of the license. The exporting country must also indicate the website address in which the licensee has advertised the transaction.

\section{Art 31(h)}

When CL is implemented in terms of this provision, the patent holder is entitled to adequate remuneration 'in the circumstances of each case, taking into account the economic value of the authorization'. ${ }^{44}$

The South African Patents Act of 1978 also substantially complies with this requirement in that s 56(2)(d) provides as one of the grounds for granting a CL that the patent holder must have refused to grant a licence or licences, 'upon reasonable terms', to the applicant for a CL.

The 2003 Decision introduced another waiver, in addition to one relating to Art 31(f), in terms of this requirement. This waiver ensures that in cases where the patented pharmaceutical is required by a WTO member country with less or no pharmaceutical manufacturing capacity, and where such patented medicine is also patented in such a country, that the granting of a CL by both the importing and exporting country will not lead to payment of royalties or licensing fees to the patent holder by both countries.

In terms of this waiver, when the royalties have been paid by the exporting country, the obligation of importing country to pay the royalties to the patent holder in respect of the same product pursuant to Art 31 (h) falls away. ${ }^{45}$

\section{December 2005 Decision}

The 2005 Decision relates to the adoption of the Protocol Amending the TRIPS Agreement. The amendment entailed in the protocol summarily relates to the substance of the 2003 Decision, and consequently pertains first, to extending the supply of pharmaceuticals manufactured through a CL

\footnotetext{
${ }^{43}$ Par 2(b)(iii).

${ }^{44}$ Art 31(h) of the TRIPS Agreement.

${ }^{45}$ Par 3 of the 2003 Decision.
} 
beyond domestic markets of WTO member states, and secondly to restricting the obligation to pay adequate remuneration to the patent holder whose patent is the subject of a compulsory license by the exporting country and not by the importing country, where a CL has been granted to the importing country for the same pharmaceutical. Effectively, this amendment introduces Art 31 bis, an additional Article after Art 31.

Member countries initially had until 1 December 2007 to accept the protocol. ${ }^{46}$ This deadline was subsequently pushed even further as the 5 December 2011 Decision extended the period of acceptance of the Protocol by members for the third time until 31 December 2013. However, on 26 November 2013, the General Council decided to further extend such a date until 31 December 2015 or such later date as may be decided by the Ministerial Conference. ${ }^{47}$

India, Norway and Canada were among the first countries to amend their patent laws to reflect the spirit of the 2005 Decision. ${ }^{48}$ The 2005 Decision has to date only been implemented by Rwanda and Canada in 2007 wherein Canada sought to assist Rwanda by exporting Canada- manufactured pharmaceuticals. The process proves to be time-consuming and heavily laden with administrative hurdles of different sorts. Most of the requirements do not appear sensitive to urgency with which access to medicines may be required by the receiving country. The non-implementation of this Decision by any other country and the fact that Rwanda has not attempted or shown interest in using this route again to access pharmaceuticals raises questions on its practicality.

In terms of this Decision it is only the LDCs that are granted an automatic qualification for 'eligible importing Member's status, however other countries that have established the lack or insufficiency of their capacity may be accommodated. Most importantly the sufficiency is determined only by capacity that resides outside ownership and control of the patent holders. ${ }^{49}$

The full impact of this decision will strongly be determined by the extent to which national laws allow for this waiver, and may only be effected when national laws have been changed to provide for such.

\section{CBD and the National Environmental Management Biodiversity Act (NEMBA)}

The influence of the international legal standards entrenched in the CBD of 1992 to which South Africa has acceded, and the Nagoya Protocol of 2010 on the CBD have introduced the requirements of prior informed consent and access to fair and equitable benefit-sharing for any party interested in

\footnotetext{
${ }^{46}$ Par 2 of Decision of the General Council of 6 December 2005 on the Amendment of the TRIPS Agreement.

${ }^{47}$ General Council Amendment of the TRIPS Agreement - Fourth Extension of the Period for the Acceptance by Members of the Protocol Amending the TRIPS Agreement (WT/L/899).

${ }^{48} 2005$ WTO Press Releases 'Members OK amendment to make healthy flexibility permanent' http://www.wto.org/english/news_e/news_e/pres05_e/pr426_e.htm

${ }^{49}$ Par (ii) of Annex: Assessment of Manufacturing Capacities in the Pharmaceutical Sector, WT/L/540, p. 5
} 
developing and commercializing IP from biodiversity and IK. These legal standards have found expression in the legal framework governing biodiversity, IP and IK in South Africa.

In a bid to implement Articles 15 and 8 (j) of the CBD, the member states adopted the Nagoya Protocol on Access to Genetic Resources and the Fair and Equitable Sharing of Benefits Arising from their Utilisation to CBD in October 2010. The main objective of the Protocol is to ensure 'the fair and equitable sharing of the benefits arising from the utilization of genetic resources and by appropriate transfer of relevant technologies, taking into account all rights over those resources and to technologies, and by appropriate funding, thereby contributing to the conservation of biological diversity and the sustainable use of its components'.50

The South African NEMBA of 2004 echoes the key objectives of the Nagoya Protocol as underpinned by Articles 5, 6, and 7 relate to fair and equitable benefit-sharing, access to genetic resources, and access to knowledge associated with genetic resources. Prior to NEMBA the right to access and appropriate indigenous knowledge (IK) was not regulated by law and so IK holders were not duly compensated for use of their valuable IK in development and commercialization of inventions or any other form of intellectual property (IP). Their right to access or own the resulting IP or share in the commercialization benefits did not exist.

The NEMBA and the Patents Amendment Act of 2005 incorporated the CBD's afore-stated position that bio-prospectors or parties seeking to conduct R\&D on biodiversity and make use of IK have to first seek informed consent and that benefit-sharing arrangements must be in place.

Further studies are necessary to examine the Protection, Promotion, Development and Management of Indigenous Knowledge Systems Bill of 2014 published in March 2015, whether IK holders in this era are now fairly served by the existing legislation, and whether the manner in which the implementation of the new pieces of legislation conducted is appropriate or requires improvement to best serve the interests of the IK holders in South Africa.

While the NEMBA and associated legal developments secured the right of the indigenous communities or IK holder and by extension the public to benefit from commercialization of patented medicines that are developed from IK, the right of IK holders to own the IP in question is not clearly upheld. Given the proven ability of IK holders to contribute in IP creation, ${ }^{51}$ the law has to take into account that the IK holder's rights may be extended to ownership of the resulting IP. This will go a long way in remedying the challenges of the public's access to patented medicines. Benefiting in commercialization of patented medicines is not synonymous with, and will not ensure, access to the

\footnotetext{
${ }^{50}$ Art 1 of the Nagoya Protocol on Access and Benefit-Sharing.

${ }^{51}$ Rhodes University researchers worked with IK holders towards the improvement of the traditional mead known as is 'Iqhilika' by the Xhosa people.
} 
patented medicines as the IK holders may be paid the royalties or portions of commercialization income that may still be inadequate to ensure access. However, the right to ownership or coownership will grant indigenous communities or the public greater advantage regarding access and use of the IP in question.

\section{The influence of the US Bayh-Dole Act}

As already indicated that the promulgation of the IPR Act in South Africa was strongly influenced by the US Bayh-Dole Act a question arises on the impact of this legislation to date in promoting access to medicines. Given that the IPR Act has only been effective for a period of about 5 years, there is no reported or published case where this legislation was used to realize the public's right to access medicines. However, the right of IP ownership that now vests on public R\&D institutions, and the objective of this legislation towards utilization of IP emanating government-funded R\&D for public good, create a promise that the State and its organs will be able to use health-related IP in the public interest, unlike the manner in which privately owned IP is used by pharmaceutical patent holders.

The provision relating to the State's walk-in rights provided in this legislation also carry a promise that IP generated from government-funded R\&D will not be abused by the institutions or licensees such as private pharmaceutical companies as the State has an irrevocable right to walk-in whenever such IP is not adequately used or abused, or when the emergency needs of country relating to health, safety, or military arise. However, the non-implementation of CL and other State walk-in type of rights provided in the Patents Act raises a question on whether the South African government will ever implement the similar type of rights provided in the IPR Act.

The US government has also never implemented the walk-in rights provided in the US Bayh-Dole Act of 1980 even when called upon to do so when the public's right to access medicines was compromised in the US. This has led some scholars to conclude that the state's walk-in are mere paper tigers or provisions that carry no meaning and that are unlikely to ever be implemented, at least in the US.

Lastly, it is equally concerning that the conditions of IP commercialization set out in the IPR Act ${ }^{52}$ are focused on regulating licensing and assignment transactions but do not decisively oblige the government-funded R\&D institutions to account for not utilizing their IP in the public interest. This current situation allows the institutions to employ their discretion regarding whether they exclusively implement revenue-focused IP commercialization strategies or pursue public interest. Institutions are therefore able to, under the IPR Act regime, prioritize high-revenue transactions over deals that would

\footnotetext{
${ }^{52}$ Ss 11 and 12.
} 
lead to provision of medicines to the public at low cost. It is recommended that this legislation be amended to oblige institutions to give priority to public interest when commercializing or utilizing IP relating to medicines, otherwise the public good objective of the IPR Act may be compromised.

\section{CONCLUSION}

For many DCs and LDCs or more specifically the African countries, the TRIPS Agreement appears to have compromised the public's access to medicines by imposing very high standards of IP protection which were not compatible with most of these countries' level of innovation, available know-how and technological infrastructure. This situation could be the reason why LDCs have to date been continually seeking extension of the cut-off date for their compliance with the TRIPS Agreement.

It can be concluded that the TRIPS Agreement negatively impacted the prospects of the South African public to access patented medicines. This is because the effect of South Africa's accession to the TRIPS Agreement is that all legal reforms or policy reviews or propositions relating to IP have to be dictated by the standards of IP protection set out in the TRIPS Agreement. The amendment of the Medicines and Related Substances Control Act in 1997 which introduced parallel importation provisions led to a law suit against the South African government. The applicant in this matter alleged that the said amendment was in contravention of the TRIPS Agreement.

For the same reason, US government also put South Africa on the Special 301 watch list in 1998 and 1999, branding South Africa as a country with no regard for IP rights and that was contravening the TRIPS Agreement. Obviously, this would not only negatively affect South Africa's international trade relations with US, but with the rest of the world. This proved that South Africa's accession to TRIPS diminished national autonomy towards policy making. The publication of the DNIPP in 2013 also brought forth a lot criticism from the developed countries, the authors of the TRIPS Agreement, as it decisively highlighted a number of changes that would ensure usher in an IP regime that befitted the South African context.

In terms of the DNIPP, the abuse of patent rights by pharmaceutical patentees is also decisively dealt with as the implementation of mechanisms such as CL, government use, and parallel importation would ensure that the pharmaceutical patent rights are not abused by excessive pricing of patented medicines, refusal to grant licenses to generic manufacturers, or in any other way that undermines the public's human right to access health care services including medicines. The DNIPP is in process of being passed by Parliament despite the overwhelming measure of concerns raised by developed countries, the pharmaceutical industry and other stakeholders. 
It is worth noting that South African legislation has long provided for CL, government use and parallel importation, even prior to the adoption of the Doha Declaration on Intellectual Property Rights and Public Health in 2003, but these provisions has to date never been implemented. The situation of the s 15c amendment of the Medicines and Related Substances Control Act proves that some developed countries such the US are capable of paralyzing the enactment or implementation of IP laws and policies that appear to threaten their interests and those of the pharmaceutical multinational companies. It is also possible that the charges laid against the South African government at the time were withdrawn on condition that parallel importation would not be implemented although part of South African law.

The response of the US, and other developed countries, to the s $15 \mathrm{c}$ amendment appeared to be insensitive to the fact that such amendment was the first to be made by a democratically elected government in the history of South Africa.

Politically, the adoption of the TRIPS Agreement was badly-timed for South Africa as it occurred barely two weeks before the country's very first democratic elections which saw the removal of apartheid regime while ushering in an inclusive regime that prioritizes respect of human rights and a better quality of life for all. It is therefore very important to note that South Africa's accession to the TRIPS Agreement was by the apartheid government and not by a government that took interest in everyone's right to access medicines, or any form of technology or product protected by IP rights. This legitimizes the argument that the South African IP law regime and more specifically the Patents Act of 1978 has not undergone any major review post the promulgation of the democratic Constitution of 1996, and hence the suggestion of legal review that will be informed by the current democratic regime.

Hirsch however unreasonably suggests that the government of the African National Congress was implicated in the adoption of the TRIPS Agreement by virtue of Professor Kader Asmal's presence in the Uruguay round of the GAAT where the WTO was established. His reasoning relies on the claim that popular prediction was that the ANC would soon come into power, and that Asmal's international experience as a legal scholar would add value to the engagements. Hirsch's assertion sounds rather ambitious if not superficial and raises a question of what impact could Asmal or the ANC have had in such an advanced level of negotiations wherein the apartheid South Africa was also arguably not as vocal as other DCs.

On the other hand, the CBD positively influenced the development of South African law through the enactment of the NEMBA and the 2005 amendment of the Patents Act which recognize the legitimacy of IK holders as proprietors of IK with valuable contribution in the development of IP in bioprospecting $\mathrm{R} \& \mathrm{D}$ projects. The NEMBA therefore, in line with the $\mathrm{CBD}$, requires the bio-prospectors 
to solicit informed consent prior to conducting $R \& D$, and that there must be benefit-sharing agreements place to protect the interests of the indigenous communities should the IP in question be commercialized.

However, further studies in this regard are necessary to ascertain the adequacy of benefit-sharing as an appropriate incentive for IK holders. Such studies must among other aspects consider the eligibility of IK holders to the right of IP ownership, particularly where IK holders did not merely provide IK and access to biodiversity but also contributed intellectually in IP development.

Overall, South Africa remains substantively compliant with the provisions of the TRIPS Agreement, the Doha Declaration on Intellectual Property and Public Health and has practically demonstrated willingness and ability to aid other Sub-Saharan African countries that have inadequate manufacturing capacity, ${ }^{53}$ a principle consistent with the 2003 and 2005 Decisions except that South Africa's aid was pursuant to a voluntary license obtained following initial refusal by the licensors, GSK and BI. Additionally, South Africa's law is indeed in compliance with the CBD, and the Paris Convention which uphold very high standard of IP protection.

It is however incumbent on South African government to ensure that the people of South Africa practically enjoy their fundamental right to access healthcare services, including medicines, by implementing the existing legislation and policy provisions that promote the public's access to medicines as it is not enough to only have world-class, progressive legislation and policies that are not implemented and which consequently offer no tangible benefit to the public.

The influence of the American Bayh-Dole Act on South Africa through the promulgation of the IPR Act may not bear much fruit for the public if the South African government, like the US government, lacks political will to walk-in and effect the public interest utilization of IP purported by the said legislation. Ownership of health-related IP by the SAMRC and other publicly-funded R\&D institutions such as universities can only be meaningful for the public if the IPR Act is amended to oblige the publicly-funded R\&D institutions to pursue public interest commercialization and not only high revenue transactions. If this is not done, the IPR Act may easily create a second tier of pharmaceutical patents abusers in the form of public $R \& D$ institutions in addition to the pharmaceutical multinational companies who have for decades distinctively played this role uncontested.

\footnotetext{
${ }^{53}$ Hazel Tau and others v GSK and BI.
} 


\section{REFERENCES}

\section{Unpublished theses}

YA Vawda ‘Access to Life-Saving Medication in South Africa: The Case for Legislative Reform' (2010) LLD Thesis submitted at the University of Kwa-Zulu Natal.

L.Ndlovu. 2014. Access to medicines and the WTO TRIPS Agreement: A study of select SADC countries. Unpublished LLD thesis submitted at the University of South Africa.

\section{Legislation and Policy}

South African Draft National Policy on Intellectual Property, Notice 918 of 2013, Government Gazette No. 36816.

South African Patents Act of 1978

South African Medicines and Related Substances Control Act of 1965

South African Intellectual Property Rights from Publicly-Financed Research and Development Act

Protection, Promotion, Development and Management of Indigenous Knowledge Systems Bill, 2014

General Council Amendment of the TRIPS Agreement - Fourth Extension of the Period for the Acceptance by Members of the Protocol Amending the TRIPS Agreement (WT/L/899).

2005 WTO Press Releases 'Members OK amendment to make healthy flexibility permanent' http://www.wto.org/english/news_e/news_e/pres05_e/pr426_e.htm

Assessment of Manufacturing Capacities in the Pharmaceutical Sector, WT/L/540

\section{Journal Articles}

NA Bass 'Implications of the TRIPS Agreement for developing countries: Pharmaceutical patent laws in Brazil and South Africa in the $21^{\text {st }}$ century, p191

J. Braithwaite and P. Drahos. 2000. Indigenous Knowledge, Intellectual Property and Biopiracy: Is a global biocollecting society the answer. European Intellectual Property Review, Vol. 22(6), pp 245-250.

R.Cardwell and P.L Ghazalian. 2012. The effects of the TRIPS Agreement on the international protection of intellectual property rights. The International Trade Journal Vol. 26(1), pp 19-36. DOI: 10.1080/08853908.2012.631868

G Ghidini 'On TRIPS impact on least developed countries’: the effects of a double-standard approach' (2014). TRIPS and developing countries: Towards a new intellectual property world order? (eds) G Ghidini, JR Rudolph and PM Ricolfi.

J.E Hill. 2014. Changes to the intellectual property policy in South Africa: putting a stop to evergreening? Expert Opinion on Therapeutic Patents, Vol. 24(8), pp. 839-843. Doi:10.1517/13543776.2014.931376. 
A. Kamperman-Sanders and D.B. Shabalala. 2014. Intellectual property treaties and development. In D. Gervais (ed.), Intellectual Property Trade and Development, Oxford University Press, Available at SSRN:http://ssrn.com/abstract=2178423

C. May and S.K. Sell. 2006. Intellectual property rights: a critical history. Boulder Publishers.

J-F Morin and E.R Gold. 2014. An integrated model of legal transplantation: the diffusion of intellectual property law in developing countries. International Studies Quarterly, Vol. 58(4), pp.781-792. DOI:10.1111/isqu.12176

L. Ndlovu. 2014. The WTO TRIPs Agreement and Access to Medicines in South Africa into democracy. Available at http://www.researchgate.net/publication 1272293198;

C Park, A Parbhala and J Berger 'Using Law to Accelerate Treatment Access in South Africa - An Analysis of Patent, Competition and Medicines Law’ (2013), United Nations Development Programme

SK Sell 'Post-TRIPS Developments: The tension between commercial and social agenda in the context of intellectual property’ (2001). 14 Fla, J Int'l L 193;

SK Sell 'Intellectual Property Protection and anti-trust in the developing world: crisis, coercion and choice' (2002) International Organisation, Vol. 49, pp 315-349

SK Sell. 2002. 'TRIPS and the Access to Medicines Campaign' (2001). Proceedings of the 2002 Conference on Access to Medicines in the Developing World: International Facilitation or Hinderance? Panel \#2: TRIPS and Access to Medicines Campaign. Wisconsin International Law Journal Vol. 20, pp. 481-522.

SK Sell 'Post-TRIPS Developments: The tension between commercial and social agenda in the context of intellectual property’ (2001). 14 Fla, J Int'l L 193;

SK Sell 'Intellectual Property Protection and anti-trust in the developing world: crisis, coercion and choice' (2002) International Organisation 49, pp 315-349

SK Sell ‘TRIPS and the Access to Medicines’ (2001). Wis. International Law Journal

S.K Sell. 2007. TRIPS-plus free trade agreements and access to medicines. Liverpool Law Review Vol. 28(1), pp41-75. DOI: 10.1007/s10991-007-9011-8.

K.C Shadlen. 2004. Challenges to treatment: the price-infrastructure trap and access to HIV/AIDS drugs. Journal of International Development, Vol. 16(8), pp. 1169-1180. DOI:10.1002/jid.1170 
K.C Shadlen. 2009. The politics of patents and drugs in Brazil and Mexico: The industrial bases of health policies. Comparative Politics Vol. 42(1), pp 41-58.

YA Vawda and B Baker 'Achieving social justice in the human rights/intellectual property debate: Realising the goal of access to medicines' (2013) 13 African Human Rights Law Journal 55-81;

C Visser 'The policy-making dynamics in intergovernmental organizations: A comment on the remarks of Geoffrey Yu’ (2007) Chicago-Kent Law Review Vol. 82(3), pp. 1457-1466.

C Visser 'AAffordable medicines exceptions to patent rights under the TRIPS Agreement: some pointers for South Africa?. (2001). Comparative and International Law Journal of Southern Africa, Vol. 34, pp. 377-396.

K. Zeng. 2002. Complementary trade structure and US-China negotiations over intellectual property rights. East Asia.

\section{International Treaties, Conventions}

Agreement on Trade Related Aspects of Intellectual Property Rights (Annex 1C of the Marrakesh Agreement Establishing the World Trade Organisation).

Convention on Biological Diversity

Nagoya Protocol on Access to Genetic Resources and the Fair and Equitable Benefit-Sharing Arising from the Utilisation to the Convention on Biological Diversity. 